\title{
TAXONOMIAS DAS DOENCAS ENTRE OS ÍNDIOS BANIWA (ARAWAK) E DESANA (TUKANO ORIENTAL) DO ALIO RIO NEGRO (BRASIL)
}

\author{
Luiza Garnelo \\ Fundação Oswaldo Cruz - Brasil \\ Dominique Buchillet \\ Institut de Recherche pour le Développment - França
}

Resumo: O presente artigo estuda as taxonomias de doenças de dois povos indígenas da região do Alto Rio Negro, Noroeste amazônico (Brasil): os Baniwa, da família lingüística arawak, e os Desana, da família lingüística tukano oriental. Tomando como base explicativa a produção mítica dessas etnias, as autoras comparam seus sistemas de doença e cura e demonstram que as circunstâncias ligadas ao surgimento de uma doença particular, as representações de pessoa e do mundo natural, e as modalidades de relação entre os grupos humanos, a natureza e o cosmos, participam da interpretação da doença. Essa ênfase na causalidade social e/ou com a ordem do mundo traduz-se na terminologia vernacular e na classificação das doenças em ambos os grupos estudados. A produção do processo patogênico liga-se a uma "economia simbólica da alteridade" (Viveiros de Castro, 2002). Promover a saúde e evitar a doença exigem cooperação, reciprocidade, diligência, controle das ações predatórias e do apetite alimentar e sexual.

Palavras-chave: etnologia, índios sul-americanos, Noroeste amazônico, saúde indígena.

Abstract: The present paper studies the disease taxonomies on two indigenous peoples from the upper Negro River region, in the Amazonian northwest (Brazil), the Baniwa, from the Arawak, and the Desana, from the oriental Tukano linguistic families. Taking these ethnies' mythic production as an explicative basis, the authors make comparisons between their disease and cure systems and demonstrate that the circumstances linked to the outbreak of a particular disease, the representation of people and of the natural world, and the modalities of relations between human groups, nature and the cosmos, participate on the disease's interpretation. Both studied groups translate this emphasis 
on social causality and/or world order into the vernacular terminology and disease classification. The pathogenic process production is linked to an "alteration symbolic economy" (Viveiros de Castro, 2002). Promoting good health and preventing disease, requires cooperation, reciprocity, diligence, predatory actions and feeding and sexual appetite controlling.

Keywords: Amazonian Northwest, ethnology, indigenous health, South American indians.

A adaptação dos projetos e das ações de saúde ao contexto epidemiológico e sociocultural local é um dos preceitos de base da política de saúde indígena, implementada pelo governo brasileiro a partir do ano de 1999. Tal preceito pressupõe, por parte do pessoal de saúde, um certo grau de entendimento e respeito com relação às características socioculturais dos povos enfocados pelas ações de saúde, em particular no tocante às suas concepções e práticas em matéria de saúde e doença. Uma barreira potencial ao acesso e à utilização, pelos índios, dos serviços da rede pública de saúde reside no desconhecimento e/ou nas percepções negativas dos profissionais de saúde em relação a essas representações e aos povos que as colocam em prática, sendo estes últimos, muitas vezes, retratados como ignorantes, promíscuos e resistentes às intervenções médico-sanitárias. Tal barreira poderia ser minimizada com a ampliação do conhecimento dessas produções culturais e o reconhecimento, pelos profissionais, de sua importância para a preservação das condições de vida e da saúde dos povos indígenas.

Este artigo compara e analisa as taxonomias de doenças de dois povos indígenas da região do Alto Rio Negro, Estado do Amazonas, no Noroeste amazônico (Brasil): os Baniwa, da família lingüística arawak, e os Desana, da família lingüística tukano oriental. Sedentários ribeirinhos, que vivem essencialmente da horticultura da mandioca amarga ${ }^{1}$ pelo sistema da coivara e da pesca, complementada pela caça e pela coleta (frutas, insetos), esses dois povos apresentam certas diferenças no plano sociocultural assim como na maneira de conceber a doença e seu tratamento. Os dados epidemiológicos disponíveis sobre a região do Alto Rio Negro como um todo apontam para o predomínio de

1 Manihot esculenta Cranz.

Horizontes Antropológicos, Porto Alegre, ano 12, n. 26, p. 231-260, jul./dez. 2006 
doenças infectocontagiosas e parasitárias, com destaque para as afecções do aparelho respiratório (incluindo a tuberculose), a malária, as parasitoses intestinais e as dermatoses, assim como um número importante de afecções mal definidas (ver Fundação Nacional de Saúde, 2002).

\section{Aspectos gerais das categorias de doencas entre os Baniwa}

Entre os Baniwa que habitam no rio Içana e seus afluentes no Brasil, a eclosão e a reprodução da doença estão correlacionadas com os temas de criação e destruição do mundo e dos seres que nele vivem. Dessa forma, classificar e diagnosticar doenças demanda o conhecimento dos ciclos míticos que tratam do surgimento e da organização do cosmos, da humanidade e da instauração das regras que regulam as relações entre os humanos e instituem os fundamentos da vida social atualmente vigente. A cura remete à instauração de estratégias de resolução de conflitos que ameaçam a ordem cósmica e social, fundada na hierarquia e troca de bens e serviços entre consangüíneos e afins, jovens e velhos, homens e mulheres.

A organização do parentesco se expressa através de três fratrias ${ }^{2}$ (hohodene, waliperi e dzawenai, com seus respectivos sibs), que são falantes da mesma língua, mas mantêm acordos matrimoniais entre si, de modo distinto dos povos tukano, cujas relações de afinidade são regidas pela exogamia lingüística. Os relatos míticos baniwa sobre doença e cura são bastante homogêneos e se configuram como unidades articuladas entre si, formando uma rede de grande coerência interna. Porém existem variações frátricas dessas narrativas (alterações no seu enredo, na descrição dos locais onde se desenrolaram as ações dos deuses e heróis criadores, e no desfecho dos eventos), sem comprometimento da integridade do conjunto. Há ainda uma hierarquia de saberes relativamente independente da distribuição frátrica dos conhecimentos e ligada ao grau de apropriação dos conteúdos da tradição, que é mais acentuado entre especialistas tradicionais, como os maliri iminali - os xamãs baniwa que viajam pelo cosmos auxiliados pelo uso do paricá ${ }^{3}$ - e os

\footnotetext{
2 As fratrias baniwa são grupos de parentesco, formados por sibs ou grupos de descendência patrilinear e patrilocais, nomeados e hierarquizados segundo uma ordem definida na mitologia do grupo (Journet, 1995).

3 Trata-se de um pó preparado com a casca da planta Virola sp e/ou Piptadenia peregrina, cuja aspiração provoca alterações da percepção e da consciência.
}

Horizontes Antropológicos, Porto Alegre, ano 12, n. 26, p. 231-260, jul./dez. 2006 
malikai ${ }^{4}$ iminali, ou donos de cânticos. ${ }^{5}$ Outras estratégias terapêuticas, como o uso de plantas medicinais, variam bastante segundo cada patrisib, assim como segundo sua distribuição nos microecossistemas de residência dos vários sibs.

A cosmologia baniwa está organizada em três ciclos. ${ }^{6} \mathrm{O}$ primeiro trata dos conflitos ancestrais travados entre a família de proto-humanos, formada pelo criador Niãpirikoli e seus irmãos, e os animais-espíritos (macacos-trovões, peixes e serpentes canibais e outros agressores), os afins com quem a família ancestral disputava o controle do cosmos. O relativo sucesso da luta da família de Niãpirikoli, em conseguir matar ou expulsar esses seres perigosos, possibilitou a existência da humanidade atual. As lutas ancestrais envolveram assassinatos, roubo, trapaças, avareza, adultério, desobediência e outros comportamentos anti-sociais, perpetrados entre afins e entre consangüíneos. Tais conflitos ameaçaram a frágil ordem social instituída por Niãpirikoli e seus irmãos, que buscavam impor ordem ao caos, limitando a agressividade vigente na ancestralidade. Nesse contexto de conflitos, a doença surge ora como arma de guerra utilizada pelos criadores ou por seus inimigos, ora como subproduto indesejado de ações mágicas que visavam a erradicar a ação agressiva dos seres-espíritos. Logrando êxito apenas parcial nas suas lutas contra os afins agressivos, os heróis ancestrais falharam em erradicar a doença, o sofrimento e a morte, deixando-os como indesejada herança para a sociedade humana que posteriormente adveio.

No segundo ciclo mítico, a família primordial estabeleceu as condições necessárias para o advento da futura sociedade humana. Aqui se completou a diferenciação entre consangüíneos e afins e definiram-se as regras que regulam o comportamento adequado junto a uns e outros. Personagens importantes desse ciclo são Amaro, a mulher primordial, e Kowai, filho de Niãpirikoli e Amaro. A ambigüidade é a característica central de Kowai, já que, por um lado,

\footnotetext{
${ }^{4}$ Malikai designa o poder mágico acumulado por Niãpirikoli e seus irmãos para combater os animaisespíritos; o poder xamânico de curar e de controlar o poder destrutivo dos eventos da natureza; um certo grupo de especialistas (os malikai iminali, ou donos de cânticos, que exercem tarefas equivalentes às dos kumua desana) capazes de curar ou agredir através de cânticos específicos; e, por fim, o cântico terapêutico (malikai) recitado em rituais de cura e de proteção à saúde (ver Hill, 1993; Wright, 1993-94, 1998).

5 Há ainda os profetas e os feiticeiros, de que não trataremos aqui (ver Wright, 2004).

6 Ver Wright (1981, 1993-94, 1998, 2004) e Garnelo (2003).
} 
ele viabilizou a reprodução da sociedade humana ao instituir os rituais pósnatais e de iniciação pubertária e, por outro, tornou-se a fonte de graves conflitos entre os consangüíneos primordiais. Tal violência culminou com seu assassinato, ao ser atirado numa fogueira pelo próprio pai. Como conseqüência desses eventos surgiram diversas doenças, como o veneno mánhene, considerado pelos Baniwa como o mais grave e freqüente agravo que incide sobre os membros de sua sociedade. Entretanto, do corpo queimado de Kowai, também nasceram as plantas medicinais, um dos mais importantes recursos terapêuticos utilizados pelos membros dessa etnia. Ele foi igualmente responsável pelo surgimento dos cânticos terapêuticos (malikai) e agressivos (hiwiathi).

Esse ciclo consolidou a diferenciação entre homens e mulheres, culminando numa guerra entre eles, cujo desfecho, desfavorável às últimas, tem importante implicação na hierarquização das relações de gênero hoje vigentes na sociedade baniwa, no surgimento das doenças ligadas à feminilidade e no controle masculino dos ritos pubertários femininos e dos cânticos terapêuticos.

No terceiro ciclo mítico, os ancestrais dos Baniwa conquistaram uma série de artefatos mágicos e tecnológicos, como a domesticação do fogo e das plantas comestíveis e medicinais e a fabricação dos utensílios domésticos.

Os Baniwa, como outras sociedades indígenas amazônicas, concebem a doença como parte indissolúvel das relações políticas travadas no plano humano ou cósmico. ${ }^{7}$ A causalidade da doença costuma ser atribuída às disputas intra e intercomunais e/ou com seres-espíritos que interagem agressivamente com os humanos. Essa "política da doença” (Albert, 1988), instituída na ancestralidade, permanece reproduzindo-se nos dias atuais e fornece o nexo explicativo inclusive para as doenças oriundas do contato interétnico. A capacidade de gerar, evitar ou curar as doenças é produto de um ativo aprendizado que visa à acumulação de poder (malikai) capaz de transformar magicamente as relações sociais e cósmicas. Saber e poder são faces indissociáveis de uma mesma realidade e seu acúmulo é viabilizado através de rígidas disciplinas corporais e espirituais que exercitam o autocontrole dos impulsos, da sexualidade, do apetite e da agressividade. Diversos eventos patológicos são desdobramentos indesejados do uso abusivo de malikai, gerando perda de controle da agressividade, doença e morte.

7 A esse respeito, ver Albert (1988) e Buchillet (1988, 1990). 
A alteridade costuma ser representada como uma fonte primordial de saber e também de perigo. Os relatos míticos mostram diversos personagens cruzando as fronteiras da consangüinidade e transgredindo normas sociais em busca de novos poderes. Os benefícios eventualmente obtidos podem ser redistribuídos entre a parentela, mas costumam também gerar pesados ônus que incidem sobre o transgressor; outras conseqüências, como individualização, quebra das regras de comportamento socialmente aceitável e agressividade exacerbada, também podem levar à morte por doença ou assassinato. Benefícios sociais, como a domesticação do fogo, a invenção de instrumentos de caça e de pesca e o cultivo de plantas alimentícias foram obtidos dessa forma, ligando-se assim a um comportamento anti-social, a uma proximidade perigosa com o “outro”, à perda dolorosa da condição humana, à poluição e à perda da integridade corporal. As representações baniwa de causalidade de doença, de cura e de morte estão contidas na idéia likoada, ou seja, um sistema de obrigações recíprocas que regula as trocas que intermedeiam as interações de reciprocidade positiva ou negativa, que os seres humanos efetuam entre si e com entidades sobrenaturais (Sahlins, 1983).

\section{Taxonomia de doenç $0^{8}$}

A lógica da taxonomia de doença é congruente não só com os eventos e contextos míticos que explicam sua origem, mas também com os modos como se dá sua reprodução atual. Nesse contexto, a classificação de doenças entre os Baniwa se relaciona a um conjunto de conflitos travados entre os diversos segmentos das sociedades humanas e não-humanas.

Conflitos no plano da afinidade

Estão ligados ao primeiro ciclo cósmico baniwa. Aqui surgiram diversas doenças ligadas às guerras travadas por Niãpirikoli com os macacos-trovões Eenonai. Nesse ciclo mítico também ocorreram a primeira morte, o apareci-

\footnotetext{
8 As informações sobre as doenças baniwa foram coletadas junto aos malikai iminali ("donos de cânticos”) de sibs hohodene, waliperi dakenai e awadzooronai, assim como junto a outros velhos conhecedores da tradição, ainda que não especialistas de cura, de sibs waliperi dakenai, koteroeni e liedaweni (fratria dzawenai), todos residentes no médio rio Içana.
}

Horizontes Antropológicos, Porto Alegre, ano 12, n. 26, p. 231-260, jul./dez. 2006 
mento de doenças graves, como koonami, que é associada à malária, e da peçonha das serpentes, que até então não eram venenosas. Essa categoria também abrange a doença walama, que resultou da flecha de zarabatana impregnada com o veneno dos macacos-trovões (Eenonai) e com a qual Niãpirikoli matou a serpente Oliámali, que havia cometido adultério com a sua esposa. Os quadros de walama podem ser causados pela agressão direta desses seresespíritos - que podem assumir a forma de macacos ou preguiças - mas também ser o produto de agressões humanas perpetradas por pajés capazes de mobilizar o poder dos trovões. As grandes tempestades, geradas pelos Eenonai ou por pajés capazes de mobilizar seus poderes, são ocasiões propícias para agressão com walama. Essa entidade nosológica multiforme pode ser considerada tanto uma doença quanto um meio de agressão, seja no plano humano (envio de walama pelo pajé), seja no supra-humano (agressões dos Eenonai, de outros seres-espíritos das águas, como os Omáwali, e das matas, como os Yóopinai, ou mesmo das constelações). Os sintomas mais freqüentes da doença são dores em pontada, nas juntas, nos músculos e na cabeça (walamanheetta, walama-yarakhewi), que podem ser acompanhadas de manifestações febris (katodakanapa, hamoali). Via de regra, as doenças walama são agudas e transitórias, encontrando resolução com o uso de plantas medicinais.

\section{Conflitos no plano da consangüinidade}

São essencialmente representados pelas doenças advindas de Kowai, no segundo ciclo mítico. Entre essas, estão as doenças mánhene. O termo mánhene, cuja tradução literal é "não se sabe”, pode significar: a) o envenenamento da comida, bebida, objetos pessoais e orifícios naturais de um inimigo; b) o veículo do envenenamento, seja ele uma planta ou outra substância (material ou simbólica) utilizada para causar dano à vítima; c) os sintomas provocados por essas substâncias no corpo dela. A variedade de venenos conhecidos pelos Baniwa é explicada a partir de suas diversas origens míticas, como, por exemplo, o nascimento de Kowai, cuja placenta gerou seres peçonhentos, como a arraia.

O mánhene é uma forma de bruxaria que ocupa um lugar central na cosmologia baniwa. Tendo sido a primeira causa de morte entre os ancestrais míticos, também é considerada a forma mais grave e mais freqüente de doença a atingir os membros do grupo (ver Garnelo, 2001; Wright, 2004). Segundo a moral nativa, o uso de mánhene simboliza um comportamento anti-social capaz 
de ameaçar o equilíbrio cósmico. Quando perpetrado por parentes, o envenenamento ameaça arruinar a ordem social, fundada na confiança e cooperação entre consangüíneos e seus afins. Tal razão é suficiente para remeter a reprodução desses eventos para o plano da alteridade perigosa.

Também ligadas a Kowai estão diversas doenças que se originaram do cumprimento inadequado dos ritos masculinos de passagem, instituídos por ele, devido à desobediência dos jovens às regras estabelecidas por seus consangüíneos mais velhos. Tais transgressões são consideradas muito graves, pois do aprendizado nos ritos pubertários depende a reprodução da ordem social pelas gerações futuras. Desde o primeiro rito celebrado por Kowai, a transgressão dos jovens se mostrou um importante elemento de desordem social, tendo gerado morte, canibalismo e outros agravos decorrentes da agressividade entre consangüíneos. A não observância dos jejuns, da reclusão, dos banhos rituais, da mortificação corporal e espiritual e de outros procedimentos de limpeza corporal e espiritual pode produzir doenças, como heekoapi ipua e walipere ipoanaa (doenças decorrentes de flechadas de estrelas) ou como mathikaim, hipolerhi e hirimaka (afecções oculares decorrentes de agressões de insetos aos iniciandos que se recusam a cumprir a reclusão adequada ao seu estado de liminaridade).

Um outro grupo de doenças ligado a Kowai, embora não restrito aos conflitos entre consangüíneos, é representado pelos “sopros" hiwiathi, o oposto simétrico dos cânticos terapêuticos malikai, que visam a fazer adoecer, matar ou causar infortúnios às suas vítimas. O termo tanto designa a ação de "soprar” um malefício em alguém através de uma recitação específica, mediada pela fumaça do tabaco, quanto designa a doença provocada pelo procedimento mágico. Os sopros hiwiathi remetem a Kowai, que ensinou a seus tios Eeri e Dzooli as recitações agressivas e as terapêuticas. Ao lado dos venenos, "sopros”, como iñaime imepékami e omáwali iwepemi, são consideradas doenças muito graves, e freqüentemente mortais; sua sintomatologia é variada, mas, em comum, apresentam sinais e sintomas como convulsões, torpor, coma, e morte. O "sopro” kooloipemi seria causador de hérnia inguinal ou umbilical.

\section{Conflitos de gênero}

Aqui estão enquadradas não apenas doenças como a gonorréia (dzawaropemi), que remete à guerra ancestral entre homens e mulheres pela posse das flautas rituais de Kowai, mas também infortúnios diversos, como 
desentendimentos conjugais e a incapacidade de algumas mulheres em cumprir adequadamente as tarefas domésticas. Nessa situação, assumem importância particular agravos como whíokali, um tipo de diarréia com sangue que decorre do cheiro característico dos peixes (pitiú) que permanece no alimento, quando a mulher que prepara a refeição não os limpa adequadamente. A doença remete ao adultério de uma das esposas de Niãpirikoli com a serpente Oliámali. Das secreções pútridas de sua genitália corrompida pelo esperma da venenosa serpente, teria surgido o pitiú dos peixes, transportando, para o domínio humano, a periculosidade intrínseca aos monstruosos afins primordiais.

Também podem ser enquadradas nesse nicho classificatório as doenças específicas da feminilidade, como abortamentos repetidos (iraidhalimi ieniphetti), insuficiência de leite materno (keettalimi), transtornos menstruais (iraidhalimi kanópa), infertilidade (meniipepemi). Tais doenças costumam ser atribuídas à ação maléfica de amantes rejeitados ou de famílias invejosas de acordos matrimoniais bem sucedidos celebrados pelos parentes da vítima. São situações ligadas à disputa por parceiros sexuais e/ou matrimoniais, que também remetem aos conflitos políticos entre grupos de parentes, inserindo-se no circuito de reciprocidades negativas.

\section{Outras formas de classificação}

Algumas categorias polimorfas e ambíguas de causalidade não são congruentes com a lógica até aqui adotada para classificar as doenças tradicionais Baniwa. Dentre essas, podem ser citadas as patologias provocadas pelos Yoópinai, seres-espíritos de grande importância nessa cultura. Segundo alguns relatos míticos, os Yoópinai seriam espíritos da floresta (Awakaróna) que perderam sua condição proto-humana por terem transgredido as regras de aprendizado xamânico, ministradas por Kowai. Tendo-se mostrado impulsivos e imprudentes no treinamento para o uso dos poderes xamânicos, que acessavam através do consumo de plantas tóxicas (whéero) e do paricá (dzaato), os aprendizes enlouqueceram e foram transformados em insetos, peixes, répteis e outros seres da natureza.

Em outras narrativas, eles surgem ora como aliados de Niãpirikoli (como Hoiniri, o “dono" da zarabatana, um Awakarónanai que ajudou o herói a matar a serpente Oliámali), ora como detentores de saberes essenciais à sobrevivência da futura humanidade, mas pouco dispostos a partilhar seus poderes com Niãpirikoli. Nessa via interpretativa, as doenças causadas por esses seres seri- 
am respostas agressivas às disputas travadas entre eles e os ancestrais míticos pelo direito de predação da vida animal e vegetal, atualizadas na busca rotineira de alimentos.

As principais doenças geradas pelos Yoópinai são hiipami e hiipamiawa, feridas na pele, de difícil cicatrização, cuja descrição é sugestiva de leishmaniose; hipolerhi, doença ocular que cursa com dor e opacidade da córnea, gerando cegueira; paixakada, nome genérico para as doenças que cursam com pus, dor, inchaço e calor no local doente, ou seja, abscessos; e papakapemi, feridas na pele que se espalham rapidamente pela superfície do corpo.

Como nem todos os Awakaróna foram transformados em Yóopinai, muitos deles permaneceram nas matas, numa interação distante - e freqüentemente agressiva - com os seres humanos que adentram a selva. As principais doenças atribuídas a eles são uma inflamação na perna associada à dor e dificuldade de andar, que pode ser acompanhada de dormência no membro (pakawa iixakawa); dores nas costas causadas por flechadas de Hoiniri; queimadura decorrente de envenenamento por urina dos Awakaróna, etc. A aparência desses espíritos da mata é assustadora, devido às suas deformidades corporais (alguns têm só a cabeça, outros têm um braço extremamente longo, um único olho, ou são muito altos, etc.). O contato imprevisto com eles deixa as pessoas em choque, com desmaios, pânico e transtorno subseqüente do sono e do comportamento.

Doenças trazidas pelo contato (ialanawi idzmikathi, "doenças de branco")

Estas não têm um nicho classificatório próprio. Elas perpassam diversos agrupamentos taxonômicos de acordo com o evento mítico que pode explicar sua origem. Assim, embora doenças como a malária estejam reconhecidas como subseqüentes ao contato, sua origem tem uma ligação direta com o ciclo mítico de disputas entre proto-humanos e seres agressivos do cosmos. De fato, a malária (kooname) é considerada como um tipo de veneno e sua origem atribuída ao corpo despedaçado de Konáwheri, um dos sogros de Niãpirikoli, morto pelo gavião Kamáthawa, como vingança pelo assassinato de um dos membros da família de Nhãpirikoli (ver Garnelo, 2001; Wright, 1999). Segundo o relato, o corpo morto de Konáwheri foi espalhado em diversos locais do Uaupés (ao sul do território dos Baniwa), onde corroeu a pedra criando "panelas" de malária. Como represália do assassinato do seu filho pelos brancos, um xamã 
uaupesino teria aberto essas "panelas”, permitindo que a doença se espalhasse em toda a região do Alto Rio Negro. Como se vê, a referência da malária aos brancos é apenas indireta.

As doenças trazidas no processo colonizatório estão ligadas às perigosas interações com o plano da afinidade, devendo o branco ser considerado como um tipo específico de cunhado potencial. Nos relatos míticos, personagens agressivos, rancorosos e perigosos assumem a forma física do branco: é o que ocorre com Kowai, com certos Awakaróna e com Oliámali, que, além de assumir a aparência do branco para manter relações sexuais com a mulher de Niãpirikoli, também a engravida, ameaçando o futuro controle do mundo pelos humanos. De seu corpo putrefato, proliferaram larvas que foram recolhidas por Niãpirikoli e posteriormente transformadas em ancestrais dos brancos e dos negros que se juntaram aos indígenas para emergir na cachoeira de Hipana, no rio Aiari, originando a humanidade atual. Essa narrativa associa diretamente o branco ao plano dos afins agressivos.

Um dos principais pontos de união entre as chamadas doenças de branco é seu caráter transmissível e os sintomas febris da maioria delas. O calor, uma característica intrínseca a essas patologias, remete a Amaro, a mulher primordial. Essa personagem central das disputas de gênero foi exilada por Niãpirikoli para fora do território baniwa depois que as mulheres perderam a guerra travada contra os homens, em disputa pelas flautas sagradas dos rituais pubertários. No exílio, Amaro ter-se-ia tornado a "mãe" dos brancos (também exilados logo após a sua emersão em Hipana), a quem teria ensinado a produzir mercadorias.

Amaro não é associada apenas aos brancos, mas também a todos os objetos considerados "quentes” pelos Baniwa, como o sal, os motores e ferramentas de metal, cuja fabricação exige altas temperaturas. Máquinas em geral, facões e espingardas guardam o calor que viabilizou sua fabricação e, analogicamente, são associados ao calor da vagina de Amaro, perfurada com uma espingarda por Niãpirikoli, para formar o canal de passagem para o nascimento de Kowai. Sendo simultaneamente associada ao calor e ao branco, Amaro é o ancestral mais freqüentemente invocado quando se trata das doenças febris trazidas pelo contato. Na linguagem esotérica dos cânticos terapêuticos, esses agravos podem aparecer não sob sua designação corriqueira de ialanawi idzmikatti, mas como rupapera sru Amaro (Hill, 1993).

Nesse contexto, as doenças de branco não são categorias autonomizadas, mas aparecem como um componente subalternizado no conjunto de nosologias tradicionais. A gênese daquelas que se individualizam e gozam de amplo reco- 
nhecimento como problema de saúde, como a malária, a diarréia com sangue e a gonorréia, remete sempre a um conjunto de explicações míticas mais gerais, que pode oferecer contexto e referência para a explicação do evento atual.

\section{Categorias nosológicas de doencas entre os Desana}

Os Desana, ou 甘mtko Masá ("gente do universo"), são um dos dezesseis povos da família lingüística tukano oriental que moram na bacia do rio Uaupés (um afluente do alto curso do rio Negro) no Brasil e na Colômbia. ${ }^{9}$ Os Tukano orientais reivindicam entre si uma origem e uma história comuns estabelecidas pelo mito de criação do mundo e da humanidade. Esse mito, que também explica a origem dos povos arawak (entre os quais, os Baniwa) e maku, narra o processo de humanização progressiva dos ancestrais da humanidade atual, ao longo de repetidas viagens subaquáticas realizadas no bojo da "canoa de transformação", entre Dia Apikõ Ditaru ("lago de leite”), que alguns índios desana, atualmente, localizam na Baía de Guanabara (no Rio de Janeiro), e a região do Alto Rio Negro.

Durante essas viagens, os ancestrais da humanidade pararam em inúmeros lugares ou "casas de transformação" na costa do Brasil, no rio Amazonas, no rio Negro e em vários de seus afluentes, onde participaram de ritos específicos. Essas viagens subaquáticas são consideradas pelos Desana como fases de gestação, de crescimento físico e de desenvolvimento humano dos pré-ancestrais da humanidade. O processo de humanização foi concluído com a diferenciação lingüística, que fundamentou a regra da exogamia lingüística (ou seja, a necessidade de casar fora do próprio grupo lingüístico) vigente entre os povos tukano orientais, e a conseqüente dispersão geográfica na região dos ancestrais dos povos atuais. ${ }^{10}$

Sendo aproximadamente 1,5 mil indivíduos no Brasil, os Desana distribuem-se em cerca de 60 comunidades misturadas a comunidades de outros povos da mesma família lingüística na bacia do rio Uaupés, ao sul do território dos

\footnotetext{
9 Na Colômbia, os Desana vivem na cabeceira dos rios Uaupés e Papuri e afluentes, como o Caño Virari, por exemplo.

${ }^{10}$ Ver as versões desana do mito da criação do mundo e da humanidade em Lana e Lana (1995), Diakuru e Kisibi (1996) e Tõrãmt Bayaru e Guahari Ye Ñi (2004).
} 
Baniwa. Alguns Desana vivem, atualmente, também no médio curso do rio Negro, assim como na cidade de São Gabriel da Cachoeira.

O povo desana divide-se em três grupos, cada qual reunindo vários sibs, isto é, grupos de filiação patrilineares e patrilocais nomeados e hierarquizados de acordo com a ordem de nascimento de seus ancestrais-fundadores: os grupos de chefes, de avôs e de servos. Os sibs de avôs (ou sibs de kumua, isto é, de xamã-rezadores), cujo líder maior era Wari Diputiro (“cabeça chata”), exerciam, a pedido dos chefes, as funções de prevenção, proteção e cura das doenças. Eles são tidos como os maiores conhecedores das tradições míticas e das encantações de proteção, de cura e de agressão (ou sopros). Os sibs de servos eram os pescadores e caçadores dos sibs de chefe, além de assumir outras tarefas, como, por exemplo, preparar o pó de ipadu ${ }^{11}$ e o tabaco e cuidar das tochas de breu durante os rituais.

Os Desana, como outros povos das terras baixas da América do Sul, distinguem várias categorias de especialistas rituais que exercem as funções de prevenção e cura de doenças segundo a fonte do seu poder e a natureza de suas práticas terapêuticas: os yea, ou xamãs-onça, e os kumua, ou xamãsrezadores. Os yea, cujo poder advém do contato estabelecido com os espíritos por meio da inalação do pó de paricá, são descritos como tendo a capacidade de se transformar em onça (daí o seu nome) para realizar certas tarefas. Eles efetuam as curas xamânicas através de diversas técnicas de manipulação do corpo (massagens, sucção, etc.) que visam a extrair do corpo do doente o objeto patogênico. O poder e as habilidades dos kumua vêm do seu grande conhecimento da mitologia e das encantações de proteção e cura, que assumem um papel primordial nos rituais terapêuticos e na manutenção da saúde. ${ }^{12}$

Para os Desana, como para os Baniwa e outros povos das terras baixas sul-americanas, o surgimento de uma doença inscreve-se num dispositivo de explicações que remete às representações do homem, às suas atividades na

\footnotetext{
${ }^{11}$ Preparado a partir das cinzas das folhas do arbusto Erythroxylum coca var. ipadu misturadas às cinzas das folhas da árvore Cecropia para ativar o alcalóide da coca. Esse pó estimula a capacidade de alerta e a memória, afugenta o sono e corta a fome. É uma das substâncias consumidas pelos kumua nas curas xamânicas.

$12 \mathrm{O}$ material analisado neste artigo foi coletado junto a kumua de diferentes sibs desana de nível hierárquico variado, que moram nas comunidades São João (igarapé Ingá, afluente do igarapé Urucu), São João Batista (rio Tiquié), Cucura (igarapé Cucura) e Santa Marta (igarapé Umari).
}

Horizontes Antropológicos, Porto Alegre, ano 12, n. 26, p. 231-260, jul./dez. 2006 
sociedade e a seu ambiente natural. As circunstâncias pessoais e históricas do surgimento de uma doença particular, as representações do mundo natural e das forças que o regem, as representações da pessoa, assim como as modalidades de relação entre os mundos humano, natural e sobrenatural participam da interpretação da doença. Conforme veremos adiante, a doença é geralmente concebida como o resultado da agressão de diversas categorias de seres (animais, seres-espíritos, outros humanos), como o testemunha, inclusive, o vocábulo mais usado para designar a doença (doreri). Doreri (“doença [de]”), forma substantiva do verbo dore ("enviar para", "mandar", "dar uma ordem para”), expressa a dimensão etiológica que prevalece entre os Desana: a da patogenia exógena.

Diversas doenças que acometem atualmente os índios são associadas a conflitos intra ou intercomunitários e/ou com seres-espíritos. Essa ênfase na causalidade social e/ou com a ordem do mundo traduz-se na terminologia vernacular das doenças. Ao lado de termos que simplesmente localizam a doença e denominam seu sintoma principal (kĩka doka boari, "apodrecimento da axila”, por exemplo), a maioria dos vocábulos de doenças estabelece uma relação de causalidade (por exemplo, wai masá doreri, “doença dos espíritos do mundo aquático”) ou de analogia (por exemplo, a doença wasuru - cobreira -, que se caracteriza por uma erupção de pústulas ao redor da cintura e cuja aparência lembra a forma da casa do wasuru, uma espécie de marimbondo) entre um sintoma da doença e um elemento do mundo natural ou da ordem do mundo (ver Buchillet, 1988).

Os Desana distinguem duas grandes classes nosográficas de doenças: as “doenças indígenas” (dipari maharã doreri, literalmente "doenças dos moradores das cabeceiras dos rios”) e as "doenças de branco” (pea masá behari, literalmente "doenças da gente do fogo", como é designado o branco por razões mitológicas ${ }^{13}$ ).

\footnotetext{
${ }^{13}$ De acordo com o mito desana da criação do mundo e da humanidade, o ancestral do branco foi o único a não temer pegar a espingarda que lhe foi proposta, assim como para os ancestrais dos povos indígenas do rio Negro, por Butari Goamt: agarrando a espingarda ele logo atirou no ar, daí o seu nome de "gente do fogo" (ver Lana; Lana, 1995; Diakuru; Kisibi, 1996; Tõrãmt Bayaru; Guahari Ye Ñi, 2004).
} 


\section{As doencas indigenas}

A classe das doenças indígenas divide-se em três subcategorias principais.

Doenças do universo

Denominadas em desana umuko pũrĩri (literalmente "dor do universo"). Elas existem desde a criação do mundo, podendo ocorrer em certos períodos do ano, particularmente na época da maturação de certas frutas. De acordo com os Desana, elas "vêm assim mesmo", sem razão nenhuma e podem afetar qualquer pessoa. Assim, contrariamente à maioria das doenças indígenas, elas não são atribuídas a uma intervenção maléfica externa. É por essa razão que elas são designadas pelo termo pũrĩri (“dor”) e não por doreri, vocábulo que implica necessariamente uma intencionalidade externa. As doenças do universo traduzem-se geralmente por sintomas vagos, que podem remeter também a outras causalidades: febre, malária, dor de cabeça, vômito, náusea, diarréia, dormência nos membros inferiores, reumatismo, inchaço localizado, entre outros. Vários mitos explicam a origem dessas doenças. Um mito coletado junto a um kumu do sib Kẽhiri (“flores/desenhos do sonho" - comunidade São João Batista, no rio Tiquié) narra, por exemplo, a origem de certas febres palustres que ocorrem no período da floração do umarizeiro ${ }^{14}$ (novembro) e no fim da safra da fruta umari (segunda metade de abril). Esses dois períodos são anunciados pelo canto dos sapos ohoká masá. Nesse mito, um Desana, que tinha casado com uma mulher-sapo, morreu de febre palustre após ter tomado caapi ${ }^{15}$ e tocado nas cuias de soprar dos sogros e cunhados. Hoje em dia, qualquer pessoa pode pegar essa forma de malária nesses dois períodos.

Numa versão do mito de Gaye, colhida entre o sib Bitiri Niari ("bem-te-vi tonto”), do antigo grupo dos avôs e que moram atualmente em São João (igarapé Ingá), Gaye foi envenenado por uma flecha de curare atirada contra ele por Ñekttutma Bupu ("avô trovão") para se vingar da morte dos seus filhos que este havia matado. Antes de morrer, Gaye voou pelos quatro cantos do mundo, onde vomitou a malária, a disenteria com sangue e a doença buari, um tipo de

\footnotetext{
${ }^{14}$ Poraqueiba sericea Thul.

${ }^{15}$ Bebida alucinógena preparada a partir do cipó Banisteriopsis sp.
} 
dormência nos membros inferiores. É por isso, dizem os Desana, que essas três doenças existem nos quatro cantos do mundo. Quem vai aos lugares onde Gaye as vomitou pode ser vítima delas.

O mito de Baaribo (“dono da alimentação”), coletado junto a vários sibs desana, conta a origem da doença poegue mesiamemeri. Furioso com uma de suas mulheres que desobedeceu à sua ordem de aguardar o dia seguinte para ir ver as roças de mandioca, Baaribo deu-lhe, por meio do seu pensamento, uma chicotada, fazendo-a cair na roça, onde ela desmaiou. É por isso, dizem os Desana, que uma mulher pode desmaiar hoje em dia na roça.

Doenças dos espíritos (e animais) da água e/ou da mata (wai/yuktt masá doreri)

Essas doenças, que se traduzem por uma constelação de sintomas vagos (febre, dor no corpo, tonteira, inchaço localizado, vômitos, pesadelos, sonhos recorrentes, desordens digestivas, etc.), são geralmente a conseqüência de um erro do doente: transgressão das regras alimentares durante as fases do ciclo biológico (puberdade, parto, morte) ou nos períodos rituais, desrespeito das regras de preparo da carne de caça, uso abusivo de plantas mágicas para caçar ou pescar ou, ainda, sobre-exploração de uma determinada espécie de caça ou peixe. Porém, a relação transgressão-doença não é automática. Na verdade, a transgressão coloca a pessoa num estado de vulnerabilidade biológica particular, durante o qual ela pode cair doente (Buchillet, 1988).

As doenças dessa categoria costumam também ocorrer em certos períodos do ano, particularmente nos períodos da piracema dos peixes grandes (aracu, surubim, etc.) dos rios, quando estes sobem os rios para desovar, ou também nos períodos de seca, quando as pessoas vão recolher os "peixes de verão" (bohori wai masá), assim como são denominados os peixinhos que, no verão, ficam presos nas pequenas coleções de água.

De acordo com os Desana, os animais e espíritos da água e/ou da mata podem afetar, material e sobrenaturalmente, uma pessoa, provocando nela diferentes tipos de desordens através do consumo de sua carne ou por meio de certas partes do seu corpo (unhas, bico, cauda ou rabo, membros), que eles projetam contra o corpo da pessoa como se fossem armas. Essa capacidade em criar doenças nos seres humanos encontra a explicação de sua origem na mitologia. Vários mitos, que integram o grande mito da criação do mundo e da humanidade, contam como certos pré-ancestrais da humanidade não ascende- 
ram à condição de ser humano, transformando-se num animal ou num espírito por alguma falha (inobservância das proibições alimentares vigentes nos períodos rituais, ${ }^{16}$ gula, incesto, perda de controle de si sob o efeito do caapi, por exemplo) cometida nas Casas de Transformação enquanto participavam de ritos específicos.

O mito da criação de gapi masú ("gente de caapi”), cujo corpo transformou-se nas variedades de caapi hoje conhecidas, narra como certos pré-ancestrais, não agüentando a tonteira dessa bebida alucinógena, puseram-se a roer uma parte do seu corpo; por causa disso, eles viraram wai masá para sempre. Os Desana costumam dizer que os pré-ancestrais da humanidade tinham o poder de criar e de se transformar em outros seres, habilidade que eles teriam perdido com sua transformação definitiva em seres humanos. ${ }^{17}$ Aqueles que viraram wai e yukt masá preservaram, no entanto, essa capacidade criativa e, por isso mesmo, eles são capazes, hoje em dia, de causar doenças nos seres humanos.

Por não terem obtido a condição plena de ser humano, esses seres-espíritos (e animais) guardaram uma grande hostilidade em relação aos humanos, agravada pelo fato de serem hoje a sua presa e comida. Essa hostilidade latente manifesta-se, sobretudo, nos períodos liminares nos quais as pessoas mostram sinais de fertilidade: o nascimento, assim como a menstruação, que expressa a capacidade procriativa da mulher, significariam para eles um aumento futuro da predação humana sobre o mundo animal. É por isso, dizem os Desana, que eles tentam agredir a mulher e a criança durante o parto e no período do pós-parto.

Conforme vimos no início, os wai e yuku masá podem agredir a pessoa com suas armas ou através do consumo de sua carne. A periculosidade no consumo da carne de algum animal ou peixe provém de vários elementos: a) características próprias (tamanho, tipo de alimentação, riqueza em sangue e gordura); b) instrumentos utilizados nos processos de aquisição (mão, anzol, puçá, rede de pesca, timbó, flecha, espingarda); c) formas de preparo da subs-

\footnotetext{
${ }^{16}$ Os Desana têm várias maneiras de diferenciar o tempo cotidiano do tempo ritual; uma delas é demarcada pela natureza dos alimentos ingeridos, já que nos períodos rituais comem-se apenas “antialimentos" (Hugh-Jones, S., 1979), como ipadu, tabaco e caapi.

${ }^{17}$ Hoje em dia, somente os yea e os kumua teriam essa capacidade de criação.
} 
tância para o consumo (ferver, assar, moquiar, temperar com sal e pimenta); d) associações mitológicas às quais o animal ou o peixe remete, sendo a doença uma repetição dos eventos mitológicos que presidiram a sua origem; ${ }^{18}$ e) estatuto biológico ou ritual do consumidor. Assim, o indivíduo consome não só as características da substância que se transformam em "armas" e atacam o interior do seu corpo, mas também os materiais e processos implicados na aquisição e no seu preparo para o consumo; esses últimos são suscetíveis de introduzir na substância natural elementos estranhos que podem agravar ou diminuir o perigo de suas características inerentes. Embora o perigo dos alimentos seja permanente, os indivíduos podem se prevenir dele tanto pelo xamanismo de descontaminação da comida, realizado no final do período liminar e que protege a pessoa na vida cotidiana até ela mudar de estatuto biológico ou ritual, quanto pelo respeito das restrições alimentares ${ }^{19}$ vigentes nas fases do ciclo biológico e também nos rituais comunitários.

\section{Doenças de feitiçaria}

A feitiçaria é uma causa importante de doença e morte nas genealogias dos sibs, sendo também uma das principais causas das doenças que afetam, atualmente, os seres humanos. A língua desana possui vários termos para se referir à ação intencional de provocar uma doença ou de matar uma pessoa, entre os quais nima ttarĩ e dohari.

Nima ttarĩ ("envenenar") refere-se à forma comum de causar dano a alguém por meio de plantas venenosas colocadas secretamente na sua comida ou bebida ou esfregadas nas suas roupas. Os efeitos desses venenos são variáveis, dependendo de sua natureza: desordens digestivas, tosse, expectoração cheia de sangue, perda de apetite, emagrecimento e outros. Embora o seu uso

\footnotetext{
${ }^{18}$ Por exemplo, um mito colhido entre vários sibs desana conta como certos peixes nasceram da gordura do corpo de Kamawerĩ, que tinha desrespeitado as restrições alimentares vigentes durante a confecção de enfeites de penas ao comer muitos peixes. Diz-se, hoje em dia, que no caso do consumo inadequado ou não protegido pelo xamanismo da carne desses peixes, a gordura pode exudar do corpo do consumidor, atraindo onças e sucuris, os quais, percebendo a pessoa como presa, atiram-se nela para devorá-la (ver Buchillet, 1988).

${ }^{19}$ Sobre a lógica das restrições alimentares, ver Buchillet $(1983,1988)$ para os Desana e C. HughJones (1979) para os Barasana.
} 
não requeira um conhecimento especializado, o feiticeiro deve cuidar para não se envenenar ele mesmo ao manipular as plantas (não tocar as plantas com as mãos, colocar um colírio de proteção nos olhos quando for a um lugar cheio de venenos, por exemplo).

Dohari, o termo desana mais utilizado, refere-se à feitiçaria praticada por meio de encantações agressivas (sopros), que são recitadas secretamente, olhando para a futura vítima, ou em cima de um cigarro que é depois acendido, no caso de ela encontrar-se geograficamente distante. Diz-se que a fumaça transporta o sopro até a vítima. Um pedaço de cigarro soprado pode também ser enterrado no chão da frente da casa da pessoa ou da entrada da comunidade que se quer "estragar". Dependendo de sua intenção, o feiticeiro pode causar uma doença leve ou grave, fácil de curar ou, ao contrário, resistente a qualquer tratamento. Ele pode também escolher uma doença que o sib ou o povo da(s) vítima(s) não sabe curar. Uma doença provocada por sopro somente pode ser curada por alguém que conheça a sua origem mitológica.

Algumas doenças são localizadas (tumor no seio, íngua na ausência de ferida, cólica menstrual, por exemplo). Certas doenças infecciosas, como a malária, a tuberculose ou a diarréia com sangue, são atribuídas a essa forma de feitiçaria. Sopros específicos podem também desfigurar uma pessoa e interferir na capacidade procriativa de uma mulher, causando a sua esterilidade, dificultando o parto, fazendo-a abortar repetidamente, dar à luz somente crianças de sexo feminino, crianças mortas ou com algum defeito físico, fazendo a mãe morrer no parto ou logo depois ${ }^{20}$ (Buchillet, 2004).

Vários são os motivos para causar dano para uma pessoa, entre os quais a inveja, a raiva, a recusa em dar ou emprestar algo, a retaliação por causa de algum dano ou injustiça cometido pela vítima, o desagrado feito a um kumu, um yee ou a um líder indígena, a vingança pela morte de um parente, etc. Os conflitos entre parentes ou vizinhos não são, no entanto, os únicos motivos para o ataque de feitiçaria. O prestígio ou o sucesso pessoal de ordem material, política ou amorosa inevitavelmente suscitam no vizinho, num membro do sib

\footnotetext{
${ }^{20}$ Sopros podem também causar outros tipos de infortúnio, como transformar um trabalhador num preguiçoso, fazer viciar uma pessoa em álcool, tabaco ou ipadu, destruir as plantas de uma roça, afetar a fertilidade das plantas ou dos animais, provocar um enchente, impedindo as pessoas de ir para a roça ou a pesca, causar pesadelos ou, ainda, impedir um rapaz de casar.
}

Horizontes Antropológicos, Porto Alegre, ano 12, n. 26, p. 231-260, jul./dez. 2006 
ou num outro com menos sorte o sentimento de inveja e o desejo de "estragar". Vários episódios recentes de doenças e mortes de líderes indígenas do rio Negro foram atribuídos pelos Desana ao "estrago" por sopros ou por venenos. A inconstância de um rapaz junto às mulheres, a competição por uma mulher, a recusa pela pretendida, ou por seus pais, de uma aliança matrimonial e/ou o abandono de uma moça antes do casamento são também motivos alegados pelos Desana para o sopro. De acordo com a mitologia do grupo, a inveja e o desejo de causar dano sempre existiram, sendo que o Avô Trovão é considerado como o iniciador do "estrago" no mundo.

Um mito do sib Wari Diputiro do igarapé Cucura narra como o Avô Trovão, furioso por não ter sido convidado por Boreka (o ancestral maior dos Desana) para participar do processo de humanização, escondeu uma jararaca debaixo do toco da árvore com a qual Boreka e seu irmão fabricariam a Canoa de Transformação. O irmão de Boreka foi mordido pela cobra venenosa e morreu, mas Boreka o fez voltar à vida por meio de uma encantação terapêutica (ver Diakuru; Kisibi, 1996). Esse foi o primeiro ato de feitiçaria praticado no mundo e, por isso, o Avô Trovão é considerado como o dono da inveja, do "estrago" e também dos sopros. A inveja e seu conseqüente desejo de agredir são uma herança dos ancestrais míticos e representam, atualmente, uma ameaça potencial (Buchillet, 2004).

Contrariamente à feitiçaria com venenos, acessível a qualquer um, aquela praticada com sopros é baseada num conhecimento especializado, fazendo parte, tradicionalmente, do aprendizado do kumu, ou xamã-rezador. As doenças atribuídas aos sopros originaram-se na mitologia, podendo ser a conseqüência da infração de uma regra social ou ritual (desrespeito da regra de compartilhar comida e outros bens com os afins, por exemplo); o subproduto indesejado da brincadeira de algum ancestral ou herói mítico; ou, ainda, o resultado infeliz da experimentação, por este último, de encantações terapêuticas no sentido de averiguar a sua eficácia (ver Buchillet, 1988, 1990).

Na verdade, as doenças atribuídas, hoje em dia, ao uso de sopros, têm um ou mais mitos específicos que recordam como elas foram criadas no tempo ancestral. O conhecimento do fundamento mítico de uma doença, que faz parte do aprendizado do kumu, revela a sua essência profunda. "Somente aquele que sabe como uma doença foi criada na mitologia é capaz de curá-la” ou, alternativamente, "deve-se conhecer as rezas boas e as rezas para estragar, sem estas, não se pode curar”, costumam dizer os kumua desana. As encantações terapêuticas e os sopros são, assim, construídos ao redor dos eventos míticos 
que presidiram a origem das doenças. Considerados como capazes de afetar a experiência íntima de um indivíduo, tais encantações são a essência do poder do kumu.

Diferentemente do que ocorre entre as fratrias baniwa, onde há uma certa uniformidade no teor dos relatos míticos sobre doença e cura, os mitos dos sibs desana relativos à origem das doenças atribuídas hoje em dia ao uso de sopros contêm diferenças significativas: nos lugares de acontecimentos míticos, na identidade dos seres míticos e, sobretudo, na natureza das doenças que originaram nessas narrativas, sendo que o "mesmo" mito pode dar conta da origem de doenças diversas, de acordo com os diferentes sibs. Isso se deve ao fato de que o acervo xamânico (constituído por versões de mitos, encantações e sopros) dos kumua dos diferentes sibs é considerado como segredo, sendo tradicionalmente transmitido apenas para os membros do sib de origem segundo a linha patrilinear (de pai para filho), através das gerações, a partir de sua revelação feita pelos ancestrais míticos fundadores do sib. Daí decorre que o saber do kumu é relativamente fixo e limitado, restrito ao saber do seu sib de origem. ${ }^{21}$ Esse fato tem uma conseqüência de ordem prática importante: os insucessos terapêuticos são, muitas vezes, atribuídos ao desconhecimento, por parte do kumu, da origem mítica da doença.

\section{As doencas de branco}

Behari, na denominação pea masá behari (“doença de branco”), tem dois sentidos: "transitório” e “que passa de um para outro" (contagioso). É o termo apropriado para denominar as doenças associadas, pelos Desana, aos brancos, cuja principal característica epidemiológica é o alto poder de contágio: varíola (hoje erradicada), sarampo, gripe, coqueluche, catapora, caxumba e diarréia. As doenças indígenas não costumam ser consideradas como contagiosas, mesmo no caso do ataque de feitiçaria xamânica de âmbito coletivo (denominado birari em desana), em que pessoas da mesma comunidade caem simultaneamente doentes (ver Buchillet, 1995).

A natureza contagiosa das doenças de branco condiz com a concepção mitológica dos brancos e dos objetos manufaturados. Ela remete, em particular,

\footnotetext{
${ }^{21}$ Essa regra não impede alguns kumua desana de trocar entre si algumas encantações potentes.
} 
a uma diferença biológica fundamental entre índios e não-índios, inscrita no mito da criação do mundo e da humanidade. Nesse mito, Suribo Goamt, que virou o ancestral dos brancos ao apoderar-se da espingarda oferecida aos ancestrais da humanidade pelo Criador, ganhou, por decisão deste último, o poder tecnológico, ou seja, a capacidade de produzir objetos manufaturados. Numa versão do sib Bitiri Niari, ele foi também o único a comer o ipadu da "imortalidade" ou de "multiplicação da gente", apesar da presença ameaçadora de animais e insetos peçonhentos na beira da cuia de ipadu. É por isso, dizem os Desana, que os brancos "mudam de pele" (ou seja, mudam de roupa), multiplicam-se rapidamente e vivem por muito tempo. Assim, eles seriam dotados de uma capacidade de reprodução extraordinária, semelhante a de seus objetos e de suas doenças (Buchillet, 1995).

Contrariamente à maioria das doenças indígenas, que são imputadas à uma intervenção externa, as doenças de branco não são atribuídas à malevolência dos brancos, sendo, pois, explicadas por certas características (natureza, cheiro, forma, cor, etc.) de seus objetos (comida, tecnologia, alimentos etc.). ${ }^{22}$ Após examinar as características clínicas das doenças de branco, estabelecendo comparações com aquelas das doenças que os afetam desde sempre, os antigos forjaram pequenas histórias para dar conta do seu surgimento no mundo indígena. Uma história coletada junto ao sib Kẽhiri conta, por exemplo, como Suribo Goamtt, que estava cozinhando miçangas de vidro numa panela, criou sem querer o sarampo, quando, inadvertidamente, deixou cair no chão a espuma de fervura que se converteu então nessa doença (Buchillet, 1995). Na verdade, deixar cair no chão a espuma de fervura é algo muito perigoso para os Desana e pode dar início a vários tipos de doenças (reumatismo, malária ou diarréia, por exemplo) ou até mesmo atrair certos espíritos da mata, que se aproximam para atacar a pessoa. É por isso que as mulheres sempre ficam vigiando a fervura. Outra história, coletada junto ao sib Bitiri Niari (ver também Tõrãmt Bayaru; Guahari Ye Ñi, 2004), liga, por sua vez, o início da gripe, da coqueluche e de um tipo de diarréia com sangue ${ }^{23}$ ao cozimento do sal para matar os seus micróbios.

\footnotetext{
${ }^{22}$ Portanto, o termo doreri, que implica necessariamente uma intencionalidade externa, não pode ser usado para denominá-las.

${ }^{23}$ Vimos que a diarréia com sangue pode também ser causada por sopros.
} 
Com o contato com os profissionais de saúde e as idéias médicas ocidentais, os Desana chegaram a associar várias doenças indígenas a certas formas clínicas da tuberculose (pulmonar e extrapulmonares), mantendo, no entanto, as explicações etiológicas originais (diferentes formas de ataque por sopros). Segundo eles, essas várias formas de tuberculose pulmonar ou extrapulmonares (óssea, intestinal, ganglionar) eram pouco freqüentes no passado, atacando uma pessoa ou outra, de vez em quando. Vale lembrar que a feitiçaria deve ser endereçada a uma pessoa específica para surtir efeito; portanto uma doença causada por feitiçaria não é, em nenhum caso, contagiosa. Observando o aumento do número de casos de tuberculose na região, em particular na sua forma pulmonar, os Desana, assim como outros povos como os Tariana (povo arawak que mora nos rios Uaupés e Papuri), criaram uma versão "branca" da doença para dar conta desse fato, que não remete à teoria indígena original sobre a causa da doença. Essa nova forma de tuberculose, cuja concepção assemelha-se àquela da medicina ocidental (reconhecimento de sua natureza contagiosa, em particular), teria sido introduzida involuntariamente pelos brancos por meio de roupas e cobertores. O diagnóstico diferencial com as formas tradicionais seria assegurado pelo resultado do exame bacteriológico de escarro: positivo na versão branca da tuberculose e negativo nas formas indígenas dessa mesma doença. Os exames médicos "não detectam nada” nas doenças causadas por feitiçaria, costumam dizer os índios (Buchillet, 2000).

Como se vê, diferentemente do que ocorre entre os Baniwa, as doenças atribuídas aos efeitos dos contatos interétnicos representam uma categoria de doença bem individualizada. Embora possa existir certa correspondência entre algumas nosologias biomédicas e determinadas doenças tradicionais (como, por exemplo, no caso da tuberculose pulmonar ou da diarréia com sangue), as duas categorias diferem, no entanto, na atribuição de contagiosidade (nenhuma doença indígena é considerada contagiosa) e também na sua origem suposta: a versão branca é atribuída aos objetos dos brancos, como o são todas as doenças de branco, e em nenhum caso à feitiçaria, como o são todas as formas indígenas de tuberculose ou de disenteria com sangue.

\section{Conclusão}

A análise das taxonomias de doença e respectivas concepções de cura evidencia mais semelhanças do que diferenças entre as produções culturais 
baniwa e desana. Ambas são pautadas pelo onipresente tema da alteridade, elemento fundamental nas relações políticas de diversos grupos indígenas amazônicos. Para ambos os grupos, os episódios de doença são a expressão física de eventos míticos específicos que, embora conservando a trama original, são atualizados e reinterpretados para oferecer respostas a eventos que cotidianamente ameaçam a integridade dos indivíduos e a continuidade da vida social. De acordo com essa sabedoria ancestral, a doença é um evento tipicamente relacional, ou seja, o produto de interações conflitivas travadas entre pessoas oriundas de diversos planos da existência, humana ou não-humana. Entre os agentes políticos de doença, cuja agressividade culminaria no "envio" de elementos materiais e simbólicos capazes de gerar patologias, encontramos um conjunto heterogêneo de seres (humanos, animais-espíritos, astros e estrelas, etc.) que entrelaçam a patogenia indígena rionegrina não apenas com a ordem social, mas também com a própria ordem cosmológica, ameaçada pelo evento disruptivo gerado pelas condutas agressivas.

Os afins agressivos, os venenos mánhene e os sopros hiwiathi entre os Baniwa e as feitiçarias nima tuarĩ e dohari entre os Desana, representam elementos prototípicos da cadeia de eventos causais capazes de gerar doenças, cuja origem está ligada a sentimentos e atitudes anti-sociais como a inveja, a cobiça, o ciúme e a avareza e outras formas de excessos, que representam o oposto dos ideais de generosidade, autocontrole, temperança, cordialidade e capacidade de compartilhar. Tais atributos, considerados como características desejáveis nos modos de vida em sociedades humanas, possibilitariam o equilíbrio entre os princípios da autonomia pessoal e interdependência entre os membros do grupo, preservando a harmonia e, conseqüentemente, a saúde. Adoecer e/ou fazer adoecer são, nesse sentido, condições que anunciam a perda da condição humana e, no limite, ameaçam a reprodução da vida social como um todo.

Na mitologia dos dois grupos, a gênese da doença e sua natureza relacional remetem o processo patogênico para uma "economia simbólica da alteridade" (Viveiros de Castro, 2002), que surge como um importante meio de enriquecer a vida em sociedade. É algo que se expressa com força nos relatos das viagens subaquáticas e das Casas de Transformação dos mitos desana e no exílio de Amaro, que possibilitou aos brancos o domínio da fabricação de mercadorias. O contato com o mundo exterior é um elemento decisivo para a renovação da vida social e a aquisição de novas experiências, tecnologias e habilidades, todas ambiguamente revestidas de alto grau de periculosidade, expressa nas epide- 
mias originadas no contato com o branco e nas doenças trazidas pelos trovões ou outros seres-espíritos do céu e da natureza. A periculosidade dos "outros” pode ser involuntária, como ocorre em certas atribuições causais desana, mas, sendo inerente à sua selvageria, impossibilita sua convivência pacífica com os membros do grupo, ainda que esta seja imprescindível à sua reprodução. É o que ocorre na perigosa interação com Kowai, que, por um lado, instaura os pilares da reprodução social baniwa e, por outro, dá origem aos mais perigosos males que dizimam a sociedade.

Essas características aludem ao que Overing (1991) denomina de uma "ética da socialidade" em grupos indígenas amazônicos, que seria simultaneamente política, estética e moral. É para essas múltiplas dimensões que remetemos a produção da saúde entre as etnias aqui estudadas; promover a saúde e evitar a doença é, finalmente, exercitar a capacidade de manter os vínculos cooperativos com seus consangüíneos e, em certa medida, com seus afins, algo arduamente praticado no dia-a-dia pela aptidão de manter relacionamentos respeitosos, tolerantes e agradáveis, através de um duro exercício de comedimento, estímulo aos bons sentimentos, à capacidade criadora e à diligência. Contrariamente, a doença é sinônimo de sujeira, de preguiça, de sentimentos e atitudes autocondescendentes e anti-sociais, que levam ao desregramento dos impulsos e desejos e, na seqüência, à predação excessiva e à impossibilidade de convivência com seus iguais. A condição de doente assinala uma excessiva proximidade com o comportamento predatório de seres não-socializados dos tempos pré-humanos, trazendo em seu bojo o risco intrínseco de conversão no "outro" e de retorno ao caos primordial. Ela ultrapassa largamente os limites da individualidade, representando uma ameaça ao tecido social como um todo.

Resta-nos agora voltar ao início do texto para problematizar o potencial interesse dessas discussões para o trabalho das equipes de saúde que atuam nos Distritos Sanitários Especiais Indígenas. Para que deveriam os profissionais de saúde conhecer as representações sociais e as práticas sanitárias dos indígenas que atendem? Na verdade, além da dimensão ética do respeito às diferenças socioculturais, um direito intrínseco de qualquer usuário de serviços de saúde, o conhecimento de repertórios como aqueles que aqui analisamos é uma condição imprescindível para para que se viabilizem interações positivas, capazes de estabelecer campos de comunicação e de inteligibilidade mútuas entre indígenas e profissionais de saúde, produzindo medidas sanitárias pactuadas e eficientes, dirigidas à preservação da saúde e ao controle dos agravos que incidem sobre a população. 
A concepção nativa de doença remete sua gênese e reprodução para o plano de relações sociais que abrangem não apenas sociedades humanas, mas também complexas interações com uma natureza que é ordenada - de acordo com o pensamento nativo - através de uma lógica societária similar àquela vigente entre as etnias aqui estudadas. Trata-se de um nível de abrangência bem distinto da restrita capacidade explicativa da biomedicina, limitada ao plano da patogenia das alterações corporais e com baixa capacidade de resposta aos determinantes econômicos e socioculturais do processo saúde-doença. Os avanços do conhecimento no campo da saúde coletiva têm demonstrado a inaptidão desse modelo de desenvolver práticas sanitárias capazes de respeitar a requerida integralidade dos cuidados de saúde e de efetivar ações intersetoriais ${ }^{24}$ visando a equacionar problemas no campo da saúde.

Os estudos sobre o processo saúde-doença e sobre a organização de sistemas, serviços e cuidados sanitários vêm-se desenvolvendo, nos últimos 30 anos, através de diversas premissas teóricas e operacionais que buscam superar o enfoque estritamente individual-biológico da vertente positivista da medicina, em favor de abordagens totalizantes, capazes de estabelecer correlações entre a qualidade de vida e os níveis de saúde de populações determinadas. Dentre as diversas propostas aí produzidas, destaca-se a da promoção à saúde, consolidada em 1986 na recomendação da Organização Mundial de Saúde (Carta de Ottawa), que adota, como princípios norteadores de formulação de políticas públicas de promoção à saúde, cinco campos prioritários de ação que devem pautar a organização de serviços de saúde: implementação de políticas públicas saudáveis; criação de ambientes favoráveis à saúde; reforço à ação comunitária; desenvolvimento de habilidades pessoais; e reorientação do sistema de saúde para a integralidade dos cuidados dispensados à população (Buss, 2003; Czeresnia, 2003). Para a população atendida pelos programas de atenção básica à saúde, a principal conseqüência prática dessa orientação é o estabelecimento de cuidados gerais dirigidos não apenas ao diagnóstico e tratamento,

\footnotetext{
${ }^{24}$ Em saúde coletiva o conceito de intersetorialidade foi desenvolvido para equacionar a potencial interveniência das condições de alimentação, habitação, saneamento, renda e trabalho, ambiente saudável, redes de suporte social, acesso à educação e aos serviços de saúde, sobre os níveis de saúde de uma determinada população e sobre a distribuição dos eventos patológicos no tecido social (Ayres et. al., 2003).
} 
mas também ao desenvolvimento de ações capazes de promover mudanças na vida social e de possibilitar tanto melhoria nas condições de moradia, trabalho e lazer quanto redução das desigualdades sociais nos espaços urbanos.

Trazendo essa discussão para o âmbito da saúde indígena, podemos observar que as premissas da promoção à saúde estão muito mais próximas dos conceitos nativos de saúde e doença do que dos diagnósticos e prescrições biomédicas, amparados na redução/supressão da constelação sintomática. Para os Baniwa e os Desana, saúde é sinônimo de vida harmoniosa, de uma punção respeitosa e sustentável dos recursos da natureza, do cultivo da beleza, dos bons sentimentos, da generosidade e da religiosidade. Trata-se, enfim, de desenvolver um grande conjunto de habilidades e atitudes que, embora não diretamente relacionadas com o campo da saúde, determinam-no de modo decisivo.

O reconhecimento do contexto sócio-simbólico como fator essencial da gênese e reprodução do processo saúde-doença, que surge como um avanço no conhecimento da saúde coletiva, é, para o pensamento nativo, uma base explicativa plenamente reconhecida na gênese do adoecimento e na conseqüente adoção ou rejeição de procedimentos de cura. A adoção dessas premissas pelos sistemas de saúde promove um encontro - ainda que sob lógicas e finalidades distintas - com a sociogênese indígena da doença e da cura. Embora o modelo hegemônico de atuação dos profissionais ainda seja o biomédico, é crescente a exigência por enfoques totalizantes na produção dos cuidados de saúde que exigem o entendimento das simbolizações e das estratégias da população para equacionar seus problemas sanitários. Tal escolha se caracteriza como uma das principais vias para a concretização das práticas de promoção da saúde (Menendez, 2003).

A apreensão da lógica intrínseca, explicativa da gênese da doença, produzida por cada grupo étnico atendido nos Distritos Sanitários torna-se uma necessidade que ultrapassa o plano apriorístico do respeito genérico à diferença cultural. Ela passa a ser, de fato, a condição fundante do relacionamento com a população atendida, a única capaz de viabilizar interações respeitosas dos limites e possibilidades de atribuição de sentidos e, conseqüentemente, da ação de cada um deles na busca de melhorias dos níveis de saúde e de vida. 


\section{Referências}

ALBERT, B. Temps du sang, temps des cendres: représentations de la maladie, système rituel et espace politique chez les Yanomami du sud-est (Amazonie brésilienne). Tese (Doutorado)-Université de Paris X-Nanterre, 1988.

AYRES, J. R. C. M. et al. O conceito de vulnerabilidade e as práticas de saúde: novas perspectivas e desafios. In: CZERESNIA, D.; FREITAS, C. M. (Org.). Promoção à saúde: conceitos, reflexões, tendências. Rio de Janeiro: Fiocruz, 2003. p. 117-140.

BUCHILLET, D. Maladie et mémoire des origines chez les Desana du Vaupés brésilien. Tese (Doutorado em ?)-Université de Paris X-Nanterre, 1983.

BUCHILLET, D. Interpretação da doença e simbolismo ecológico entre os índios Desana. Boletim do Museu Paraense Emílio Goeldi: Série Antropologia, Belém, v. 4, n. 1, p. 27-42, 1988.

BUCHILLET, D. Los poderes del hablar: terapia y agresión chamánica entre los indios Desana del Vaupes brasilero. In: BASSO, E.; SHERZER, J. (Coord.). Las culturas nativas latinoamericanas atraves de su discurso. Quito: AbyaYala, 1990. p. 319-354. (Col. 500 años).

BUCHILLET, D. Contas de vidro, enfeites de branco e "potes de malária”: epidemiologia e representações de doenças infecciosas entre os Desana. Brasília: Universidade de Brasília, 1995. (Série Antropologia 187).

BUCHILLET, D. Tuberculose, cultura e saúde pública. Brasília: Universidade de Brasília, 2000. (Série Antropologia 273).

BUCHILLET, D. Sorcery beliefs, transmission of shamanic knowledge and therapeutic practice among the Desana of the Upper Rio Negro region (Brazil). In: WHITEHEAD, N.; WRIGHT, R. M. (Ed.). In darkness and secrecy: the anthropology of assault sorcery and witchcraft in Amazonia. Durham: Duke University Press, 2004. p. 109-131.

BUSS, P. Uma introdução ao conceito de promoção à saúde. In: CZERESNIA, D.; FREITAS, C. M. (Org.). Promoção à saúde: conceitos, reflexões, tendências. Rio de Janeiro: Fiocruz, 2003. p. 15-38. 
CZERESNIA, D. O conceito de saúde e a diferença entre prevenção e promoção. In: CZERESNIA, D.; FREITAS, C. M. (Org.). Promoção à saúde: conceitos, reflexões, tendências. Rio de Janeiro: Fiocruz, 2003. p. 39-54.

DIAKURU; KISIBI. A mitologia sagrada dos antigos Desana do grupo Wari Diputiro Põrã. Coletânea de narrativas míticas organizada por D. BUCHILLET. Cucura: Unirt; São Gabriel da Cachoeira: Foirn, 1996. (Coleção Narradores Indígenas do Rio Negro, v. 2).

FUNDAÇÃO NACIONAL DE SAÚDE. Distrito Sanitário Especial Indígena. Relatório de gestão 2000-2002. São Gabriel da Cachoeira, 2002.

GARNELO, L. (Org.). Manual de doenças tradicionais baniwa. Manaus: Ed. Universidade do Amazonas, 2001.

GARNELO, L. Poder, hierarquia e reciprocidade: os caminhos da política e da saúde no grupo indígena baniwa. Rio de Janeiro: Fiocruz, 2003.

HILL, J. Keepers of the sacred chants: the poetics of ritual power in an Amazonian society. Tucson: The University of Arizona Press, 1993.

HUGH-JONES, C. From the milk river: social and temporal process in Northwest Amazonia. Cambridge: Cambridge University Press, 1979.

HUGH-JONES, S. The palm and the Pléiades: initiation and cosmology in Northwest Amazonia. Cambridge: Cambridge University Press, 1979.

JOURNET, N. La paix des jardins: structures sociales des indiens Curripaco do Haut Rio Negro (Colombie). Paris: Institut d'Ethnologie, Musée de L’Homme, 1995. (Mémoires de l'Institut d'Ethnologie XXXI).

LANA, F. A. (Umusĩ Pãrokũmu); LANA, L. G. (Tõrãmt Kehíri). Antes o mundo não existia: mitologia dos antigos Desana-Kehíripõrã. São João Batista: Unirt; São Gabriel da Cachoeira: Foirn, 1995. (Coleção Narradores Indígenas do Rio Negro, v. 1).

MENENDEZ, E. Modelos de atención de los padecimientos: de exclusiones teóricas y articulaciones prácticas. Ciência \& Saúde Coletiva, Rio de Janeiro, v. 8, n. 1, p. 185-208, 2003.

OVERING, J. A estética da produção: o senso de comunidade entre os Cubeo e os Piaroa. Revista de Antropologia, n. 34, p. 7-33, 1991. 
SAHLINS, M. Economía de la Edad de Piedra. Madrid: Akal: Universitaria, 1983.

TÕRÃMU BAYARU (Wenceslau Sampaio Galvão); GUAHARI YE ÑI (Raimundo Castro Galvão). Livro dos antigos Desana-Guahari Diputiro Porã. Coletânea de narrativas míticas organizada por D. BUCHILLET. São João: ONIMRP; São Gabriel da Cachoeira: Foirn, 2004. (Coleção Narradores Indígenas do Rio Negro, v. 7).

VIVEIROS DE CASTRO, E. B. V. O nativo relativo. Mana, Rio de Janeiro, v. 8, n. 1, p. 113-148, 2002.

WRIGHT, R. M. The history and religion of the Baniwa peoples of the Upper Rio Negro Valley. Tese (Doutorado)-Stanford University, Stanford, 1981.

WRIGHT, R. M. Umawali: Hohodene myths of the Anaconda, father of fish. Bulletin de la Société Suisse des Américanistes, n. 57/58, p. 37-48, 1993-94.

WRIGHT, R. M. Cosmos, self and history in Baniwa religion: for those unborn. Austin: University of Texas Press, 1998.

WRIGHT, R. M. (Org.). Waferinaipe Ianheke: a sabedoria dos nossos antepassados: histórias dos Hohodene e dos Walipere-Dakenai do rio Aiari. São Gabriel da Cachoeira: Acira: Foirn, 1999. (Coleção Narradores Indígenas do Rio Negro, v. 3).

WRIGHT, R. M. The wicked and the wise men: witches and prophets in the history of the Northwest Amazon. In: WHITEHEAD, N.; WRIGHT, R. M. (Ed.). In darkness and secrecy: the anthropology of assault sorcery and witchcraft in Amazonia. Durham: Duke University Press, 2004. p. 82-109. 